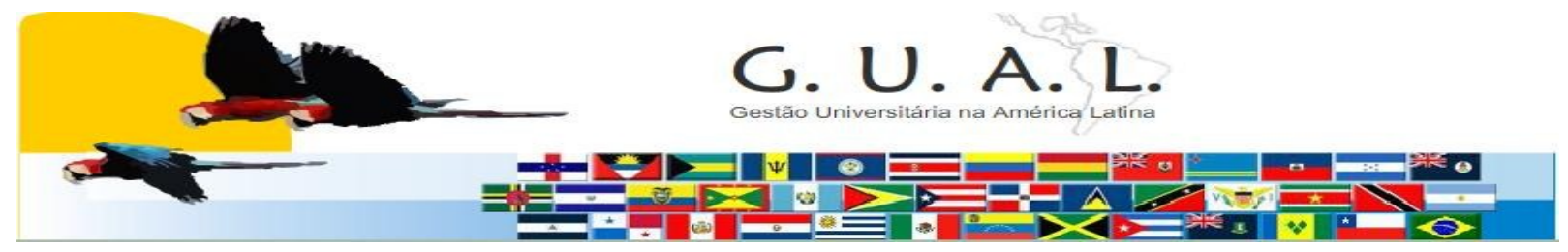

ISSN 1983-4535

\title{
COMPARAÇÃO INTERNACIONAL ENTRE CUSTOS UNIVERSITÁRIOS
}

\author{
Thiago Coelho Soares, Mestre \\ Universidade do Sul de Santa Catarina \\ thiago.soares@unisul.br \\ Gisele Mazon, Mestre \\ Universidade do Sul de Santa Catarina \\ gisele.mazon@unisul.br \\ Ailton Nazareno Soares, Doutor \\ Universidade do Sul de Santa Catarina \\ ailton.soares@unisul.br
}

\section{RESUMO}

Este artigo consiste, objetivamente, em uma análise comparativa do custo por aluno entre universidades de distintos países. Todavia, buscou-se coletar informações referentes a esta problemática. Para tanto, foram realizadas entrevistas com personalidades que pudessem elucidar esta problemática. Os resultados revelam a importância de observarmos com cuidado as diferenças internacionais na educação superior. Desta feita, uma adequação do sistema brasileiro ao sistema europeu ou norte-americano seria importante. Portanto, concluiu-se que as comparações internacionais devem respeitar pelo menos dois fatores basilares: poder de compra no país e nível de pesquisa na instituição universitária. Desta maneira, as comparações internacionais entre as universidades serão menos distorcidas, o que facilitará possíveis negócios.

Palavras-chave: Educação superior. Custo por aluno. Internacionalização. 


\section{INTRODUÇÃO}

Conforme Guerra e Carvalho (2004) cada vez menos a imagem tradicional do comércio entre países, acompanhado de um crescente aumento dos investimentos internacionais e tendo como principais intervenientes quase que exclusivamente as grandes empresas, não é adequada à realidade. Desta maneira, o desafio da modernização tecnológica e da nova gestão empresarial deve ser interpretado como uma oportunidade para o desenvolvimento da competitividade, isso porque a rápida e eficaz inovação tecnológica permitem alcançar ganhos de produtividade, qualificações dos recursos humanos, aumento da qualidade e da confiabilidade de produtos e serviços, redução do consumo de matérias-primas e subsidiárias, e particularmente de energia, por unidade produzida, adequação da gestão empresarial às políticas de proteção ambientais e aos esforços de internacionalização. Estes são os fatoreschave de competitividade que devem permitir gerar valor agregado, rentabilidade e recursos financeiros adequados, essenciais no esforço de desenvolvimento das vantagens das empresas modernas.

A universidade é caracterizada, segundo Vahl (1991) pela indissociabilidade entre as funções de ensino, pesquisa e extensão. Este tripé proporciona o desenvolvimento da educação e por conseqüência da sociedade onde estas estão inseridas. Todavia, uma universidade que apresentar a pesquisa e a extensão de forma mais robusta acaba gerando um gasto maior, o que por conseqüência gerará um custo por aluno mais elevado também.

A Assessoria Econômica do Ministério do Planejamento (2005) apresentando dados da OCDE, identifica que os gastos do governo geral no Brasil com educação superior, em 2002, totalizaram $0,9 \%$ do PIB, enquanto que os gastos do governo sul-coreano foram de $0,3 \%$ do PIB. Em contrapartida, ao apresentar dados do Banco Mundial referentes ao mesmo ano, verifica-se que a taxa de matrícula, definida como a proporção de pessoas em idade universitária matriculadas em universidades era de 85\% na Coréia do Sul e de 18\% no Brasil.

Amaral (2005) afirma que as comparações internacionais são difíceis de se realizarem. Por que, se em determinado país as instituições de ensino superior são responsáveis pela manutenção de hospitais universitários, que prestam assistência médica à população carente, mantêm orquestras, bibliotecas comunitárias, museus, escolas de ensino fundamental, educação média etc. e, em seus orçamentos, estão presentes os pagamentos de aposentados e precatórios, e se em outro país essas despesas não estão presentes, os seus custos só são 
comparáveis com a introdução de adaptações que produzam compatibilidade de suas atividades e de seus gastos.

Ter conhecimento dos custos em Instituições Universitárias em diferentes países é essencial para poder realizar comparações realistas. A partir desta problemática, pode-se dizer que estabelecer padrões internacionais de comparação da educação superior é essencial para resolver possíveis distorções causadas por metodologias utilizadas que muitas vezes não levam em consideração informações relevantes sobre a educação superior.

O objetivo geral deste artigo consiste em mostrar a dificuldade que existe na comparação entre os valores dos custos por aluno entre universidades de diferentes países.

\section{REVISÃO BIBLIOGRÀFICA}

Após a apresentação, no item anterior, dos objetivos do estudo, bem como o tema e problema de pesquisa. Apresentar-se-á neste segundo item, os aspectos que sustentam este estudo através da revisão bibliográfica, destacando as comparações do custo por aluno e de pesquisa.

\subsection{Comparação do custo por aluno}

Apesar de a educação ser fator-chave no desenvolvimento social e econômico do país, Magalhães et al (2010) afirma que os recursos públicos aplicados para este fim são escassos para atender de forma adequada a sociedade. A sociedade é responsável por parte de seu provimento e por esta razão tem o direito de exigir eficiência na aplicação dos recursos.

Comparações internacionais do custo por aluno são difíceis de serem realizadas por diferentes fatores apontados por Sheehan (1996) como políticas de ingressos nas universidades, situação legal das instituições de ensino superior, o quadro de pessoal, a tradição administrativa, as leis do país, etc.

De acordo com Amaral (2002) o custo por alunos nas instituições universitárias sofrem influência fundamental da política de ingresso de cada país.

Sheehan (1996) aponta três formas diferentes de ingresso na educação superior, são elas:

1. política de ingresso fechada: utiliza métodos como o vestibular para selecionar os alunos que irão ingressar na educação superior. Ex: Brasil, países do leste europeu, etc; 
2. política mista de ingresso: existem provas de admissão para alguns cursos e para outros não. Ex: França, cursos como medicina e engenharias, existem provas para a admissão;

3. política de ingresso relativamente aberto: como a Itália, onde as mensalidades são praticamente zero. Na Argentina, nos anos de 1883 a 1985 se abriu o ingresso dos estudantes na graduação, o que triplicou o número de estudantes. Por esta razão, houve uma redução significativa do custo por aluno.

Quando são realizadas comparações internacionais, segundo Schwartzman (1996), a interpretação dos dados é uma atividade mais complexa do que a comparação entre universidades de um mesmo país. Para o autor, as dificuldades mais marcantes estão na possibilidade de inclusão no orçamento os gastos com os aposentados, além de diferenças no nível de terceirização, do papel do hospital universitário e a existência de pós-graduação e pesquisa significativas.

Assim, para Sheehan (1996) uma boa alternativa para comparações internacionais do custo por aluno seria através da proporção do custo por aluno em relação ao PIB per capto. Esta metodologia, segundo o autor é a utilizada pela OECD (Organização de Cooperação para o Desenvolvimento Econômico) e outras organizações internacionais.

Tabela 1 - Comparação internacional do custo por aluno em 2000

\begin{tabular}{lccccc}
\hline \multicolumn{1}{c}{ País } & $\begin{array}{c}\text { Custo por aluno no } \\
\text { ensino superior } \\
\text { US\$/ano }\end{array}$ & $\begin{array}{c}\text { PIB } \\
\text { Bilhões }\end{array}$ & $\begin{array}{c}\text { População } \\
\text { Milhões }\end{array}$ & $\begin{array}{c}\text { PIB } \\
\text { per capta }\end{array}$ & $\begin{array}{c}\text { Custo aluno/ } \\
\text { PIB per capto }\end{array}$ \\
Jamaica & 6.039 & 10 & 2,6 & 3.731 & 1,62 \\
Paraguai & 4.484 & 26 & 5,6 & 4.679 & 0,96 \\
Argentina & 11.724 & 476 & 37 & 12.865 & 0,91 \\
Estados & 25.310 & 9.963 & 275,5 & 36.163 & 0,70 \\
Unidos & 4.263 & 1.130 & 172,8 & 6.539 & 0,65 \\
Brasil & 6.528 & 153 & 15,1 & 10.139 & 0,64 \\
Chile & 1.495 & 21 & 8,1 & 2.580 & 0,58 \\
Bolívia & 4.554 & 915 & 100,3 & 9.123 & 0,50 \\
México & 1.925 & 31 & 3,3 & 9.394 & 0,20 \\
Uruguai & & & & & \\
\hline
\end{tabular}

Fonte: Soares e Cericato (2005)

Schwartzman (1996) afirma que comparação em dólares nem sempre é sensata, pois as cotações no período não refletem necessariamente a paridade do poder de compra da moeda entre diferentes paises. Para efeito de comparações internacionais a interpretação dos dados é 
ainda mais problemática que em comparações entre instituições universitárias do mesmo país. Isso porque, as estruturas organizacionais são muito diferentes e a existência de pósgraduação e pesquisa significativas também interferem no resultado. Outros indicadores importantes que podem gerar distorções são: gastos com aposentados, nível de terceirização, o papel do hospital universitário.

Tabela 2 - PIB per capita: Taxa média anual de crescimento entre 1996/2005 e valor em 2004, em US\$ ajustados pela paridade do poder de compra.

\begin{tabular}{lccc}
\hline Países & $\begin{array}{c}\text { Crescimento médio } \\
\text { anual (1996/2005) }\end{array}$ & $\begin{array}{c}\text { Valor em 2004 (US\$ } \\
\text { ajustados pela PPP) }\end{array}$ \\
\hline Estados Unidos & $2,2 \%$ & 39.710 \\
G7 & Japão & $1,0 \%$ & 30.040 \\
& Alemanha & $1,2 \%$ & 27.950 \\
& Reino Unido & $2,4 \%$ & 31.460 \\
França & $1,7 \%$ & 29.320 \\
Outras & Itália & $1,2 \%$ & 27.860 \\
Economias & Canadá & $2,4 \%$ & 30.660 \\
Avançadas & Austrália & $2,4 \%$ & 29.200 \\
& Coréia do Sul & $3,7 \%$ & 20.400 \\
Émergentes & Espanha & $3,1 \%$ & 25.070 \\
Ásia & Portugal & $1,6 \%$ & 19.250 \\
\hline \multirow{2}{*}{ Europa } & China & $7,7 \%$ & 5.530 \\
& Índia & $4,4 \%$ & 3.100 \\
\hline África & Polônia & $4,1 \%$ & 12.640 \\
& Rússia & $4,3 \%$ & 9.620 \\
\multirow{3}{*}{ América Latina } & África do Sul & $1,7 \%$ & 10.960 \\
& Argentina & $0,9 \%$ & 12.460 \\
& Brasil & $0,7 \%$ & 8.020 \\
& Chile & $2,8 \%$ & 10.500 \\
& México & $2,1 \%$ & 9.590 \\
& Venezuela & $-0,5 \%$ & 5.760 \\
\hline
\end{tabular}

Fonte: FMI e Banco Mundial (apud CNI, 2006).

\subsection{Comparação de pesquisa}

No Brasil, conforme Dimenstein (2001) a maior parte do investimento em pesquisa é feito pelo governo e pelas universidades. As empresas gastam em torno de um terço do total. 


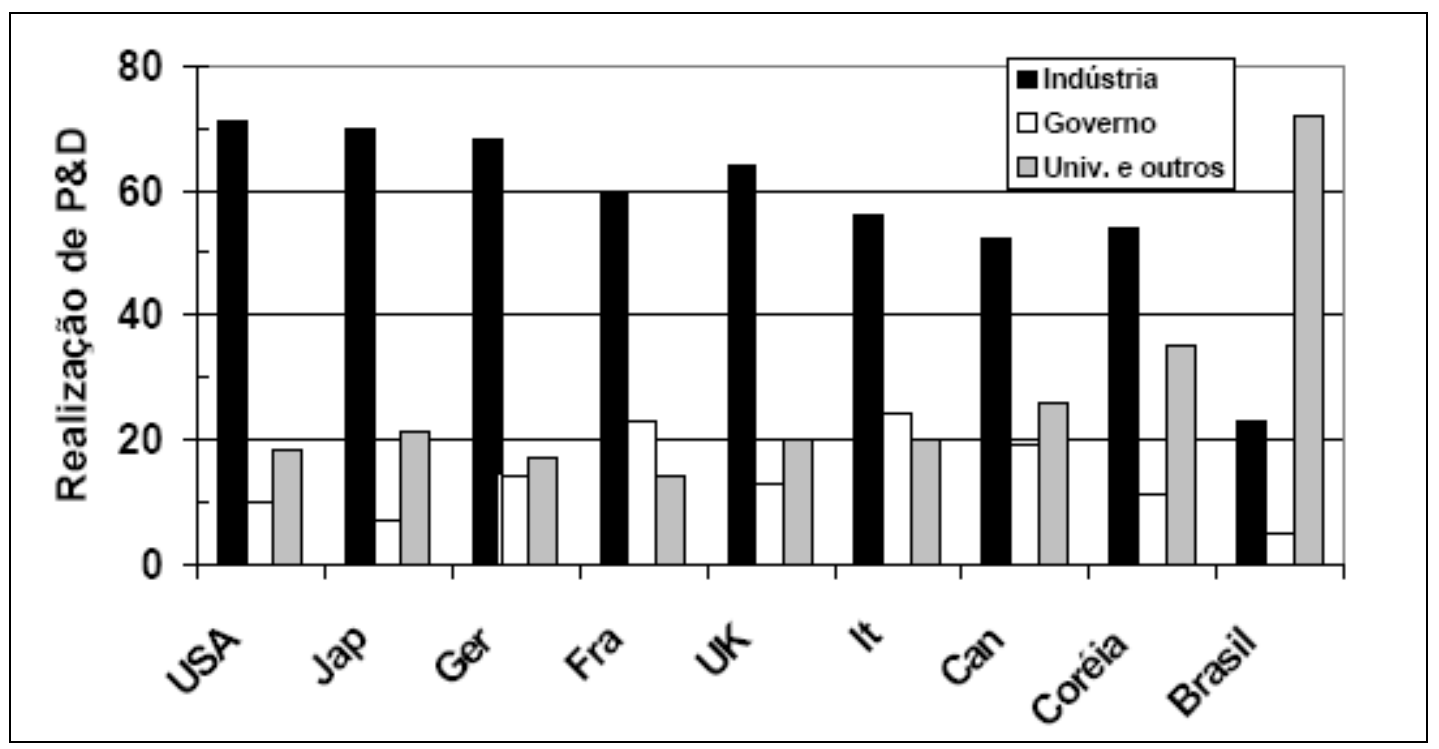

Figura 1 Distribuição dos cientistas e engenheiros ativos em P\&D Fonte: Cruz (2004)

Conforme Cruz (2004) no Brasil 73\% dos cientistas e engenheiros exercem atividade profissional nas instituições de ensino superior, como docentes e apenas $11 \%$ trabalham para empresas. Já em outros países como os Estados Unidos a maioria dos cientistas e engenheiros trabalha para empresas, atingindo a espantosa cifra de 764.500 cientistas e engenheiros industriais. Essa distribuição americana é a verificada em todos os países industrializados, com pequenas variações.

Para Silveira (2005) o Brasil conquistou uma posição de destaque na produção científica e na geração de tecnologia. Das 20 maiores instituições que mais fazem pesquisa na América Latina, 11 estão no Brasil.

Conforme Izique (2002) o Brasil investe cerca de 1\% do Produto Interno Bruto (PIB) em pesquisa e desenvolvimento, algo em torno de US\$ 5 bilhões. Pelo menos $60 \%$ desses gastos, US\$ 3 bilhões, portanto, são de responsabilidade do setor público. Porém, grande parte deste valor é gasto com a importação de máquinas e matéria-prima. Segundo a autora, cerca de $30 \%$ do valor total investido em pesquisa e desenvolvimento são gastos com produtos importados, o que eleva o custo da pesquisa no país.

Conforme Soares e Cericato (2005) existem várias metodologias para se realizar o cálculo do custo por aluno e fica inviável identificar uma correta. Por esta razão, fíca difícil a realização de comparações do custo por aluno entre as instituições de ensino superior. Salvo quando se sabe que todos os valores analisados são provenientes de uma mesma metodologia. 
Quando a comparação do custo por aluno é feita entre países a situação é complexa também. Isso porque existem variáveis como políticas de ingressos nas universidades, quadro de pessoal, a tradição administrativa, as leis do país, entre outras que interferem diretamente na relação custo e aluno.

Segundo Lobo e Filho (2004) na maioria dos países, e o Brasil não é exceção, o custo direto do ensino é cerca de um terço dos gastos de uma Instituição de Ensino Superior (IES), que incluem administração, biblioteca, esporte, transporte, segurança, manutenção, gestão acadêmica, investimentos, impostos (em alguns casos) etc. - sem falar nos gastos que algumas com pesquisa e extensão. E complementam dizendo que uma universidade que pesquisa custa mais caro por aluno do que uma instituição voltada somente ao ensino

\section{METODOLOGIA}

Lakatos e Marconi (1992) salientam que não existe ciência sem a aplicação de métodos científicos. Desta maneira, procurar-se-á expressar os métodos de pesquisa utilizados nesta pesquisa.

A pesquisa apresenta um caráter qualitativo. De acordo com Vieira (2004) a pesquisa qualitativa é definida como a que se fundamenta, sobretudo em análises qualitativas, assim não utilizando instrumental estatístico.

Quanto aos fins pode ser considerada descritiva e explicativa. Descritiva, pois está interessada em descobrir e observar fenômenos, procurando descrevê-los, classificá-los e interpretá-los sem nenhuma interferência do pesquisador. Para Churchill (1987) pesquisa descritiva objetiva conhecer e interpretar a realidade sem nela interferir para modificá-la. A pesquisa descritiva expõe as características de determinada população ou de determinado fenômeno, mas não tem o compromisso de explicar os fenômenos que descreve, embora sirva de base para tal explicação. Também é explicativa porque, de acordo com Vergara (1998), busca esclarecer quais fatores contribuem para a ocorrência de determinado fenômeno.

Quanto aos meios de investigação, este trabalho foi dividido em duas etapas, uma inicial que foi a pesquisa bibliográfica, e outra final que foi a pesquisa documental e entrevistas.

Conforme Vergara (1998) a pesquisa bibliográfica é um estudo sistematizado desenvolvido com base em material publicado em livros, revistas, meios eletrônicos e jornais. Fornece instrumental analítico para a pesquisa. 
Yin (2001) afirma que a documentação é uma fonte estável de coleta de dados, tendo em vista que pode ser revista inúmeras vezes, além de ser exata por conter nomes, referências e detalhes como também possui uma ampla cobertura, pois abrange longos períodos de tempo e espaço. Porém, o autor ressalta que o acesso aos documentos pode ser dificultoso e caso não seja realizado uma pesquisa completa pode tendênciar a pesquisa.

Foram feitas entrevistas com informantes-chaves, que são personagens com conhecimento de causa para subsidiar os investigadores na solução do problema proposto. Foram entrevistados cinco professores com doutorado em Universidades européias e que exercem funções de dirigentes e/ou docentes em Universidades do estado de Santa Catarina. Segundo Yin (2001) as entrevistas são conversas guiadas com o intuito de levantar informações necessárias para a pesquisa. Os entrevistados fornecem ao pesquisador percepções e interpretações sobre o assunto.

Minayo (1998) entende que a análise dos dados, no tocante a pesquisa científica, deve atender a três finalidades: a primeira seria estabelecer uma compreensão dos dados que foram coletados, a segunda seria a de confirmação ou não dos pressupostos da pesquisa, a terceira seria ampliar o conhecimento sobre o assunto pesquisado.

Os dados primários foram tratados com a técnica de análise de conteúdo, no que se refere às questões abertas.

A análise de conteúdo foi empregada, pois, de acordo com Richardson (1989) é utilizada para a análise de material obtido na coleta de dados de forma qualitativa, ao qual não se pode utilizar técnicas estatísticas. A análise do conteúdo é definida como um conjunto de técnicas de análise de comunicação que visa obter, por meio de procedimentos sistemáticos e objetivos de descrição de conteúdo das mensagens, indicadores que permitam inferir conhecimento relativo às questões de percepção das mensagens obtidas.

\section{ANÁLISE DOS RESULTADOS}

A descrição dos resultados, nesta secção, referem-se as entrevistas realizadas com o público-alvo da pesquisa sobre o tema a ser abordado. Como salientado anteriormente, foi utilizada a técnica de análise de conteúdo.

Foram elaboradas quatro perguntas básicas sobre o tema a ser explorado, e a partir destas são apresentados os resultados da pesquisa. 
No que se refere a primeira pergunta realizada, Como você analisa a Educação Superior no Brasil quando comparada a outros países? Pode-se observar que:

- falta à Educação Superior no Brasil investimento em pesquisa e um maior interrelacionamento Universidade e empresa, para que exista transferência dos conhecimentos criados.

- a seriedade e respeito dos alunos aos horários, permanência em sala de aula e atividades definidas, ou seja, um pouco mais de formalidade evitando chegadas em atraso, entra e sai em sala de aula.

- comparando com o modelo Europeu, em especial com as diretivas da "convenção de Bolonha" os cursos de graduação (Bacharelatos) no Brasil têm uma carga horária maior e aproximadamente mais dois semestres, que os graus idênticos conferidos por Universidades Européias. Esta maior carga horária limita a pesquisa e a investigação individual. Diferenças tão acentuadas na estrutura dos graus superiores, entre o Brasil e a Europa, resultam em modelos pouco compatíveis e a meu ver numa perda de competitividade do Brasil, onde no ciclo inicial da formação superior os estudantes têm de permanecer, em média, mais um ano nas Universidades.

Cabe ressaltar que as principais diferenças entre a Educação Superior no Brasil com relação aos demais países esta na carga horária dos cursos, a excessiva manutenção do conhecimento nas Universidades, sendo praticamente insipiente a relação Universidade/empresa e o desinteresse de alguns alunos com relação aos aspectos formais de horários. Estas diferenças acabam gerando, principalmente uma limitação na produção científica nacional, que para piorar, não é disponibilizada para as empresa de forma substancial.

Referente a segunda pergunta, Quais ações no âmbito nacional deveriam ser tomadas para melhorar a Educação Superior no nosso país?, observou-se que:

- um reforço da avaliação das instituições de ensino superior, priorizando a avaliação da "empregabilidade" das instituições: a sua capacidade de formar graduados com as capacidades exigidas pelo mercado.

- diminuição nos "currículos" das graduações, adequando o "modelo brasileiro" as tendências européias e Norte-Americanas. Num mundo globalizado, torna-se fundamental o Brasil estar em convergência com as práticas e os modelos dos países que conseguiram um maior progresso e riqueza. 
- obrigatoriedade do ensino de idiomas, ensinando-se e exigindo-se, para a conclusão de qualquer curso superior, fluência em dois idiomas (Inglês e Espanhol preferencialmente).

- obrigatoriedade do ensino de Informática e Tecnologias da informação em todas as áreas do conhecimento.

- investimento em ciência e tecnologia, grupos e projetos de pesquisa com envolvimento dos alunos, núcleos de estudo, maior adaptação da teoria e casos utilizados a realidade brasileira são ações possíveis de serem realizadas.

A guisa de síntese das percepções dos entrevistados indica que o país deve investir em uma adequação dos "currículos" dos cursos de graduações para adequá-los aos praticados em países europeus e nos Estados Unidos. Além disso, é necessária a introdução dos conhecimentos de idiomas e informática para um nivelamento dos egressos das Universidades brasileiras em nível internacional.

Quanto ao Âmbito institucional, quais seriam estas ações?, as respostas mais comuns dos informantes chaves foram:

- dedicar o primeiro semestre, de todas as graduações, a uma formação propedêutica priorizando: Ensino de idiomas; Ensino de Português; Ensino da metodologia e técnicas de pesquisa; Ensino de Informática e Tecnologias da Informação; Pesquisa na Internet; Português, Comunicação Oral e Escrita; Matemática, lógica e Cálculo; Ciências Sociais; Ética e Cidadania; Direito e quadros Institucionais da Vida Econômica e Social.

- reforço da exigência de exclusividade do Corpo docente, privilegiando professores com dedicação integral.

- criação de um corpo docente estável e qualificado, garantindo uma cultura organizacional sólida.

- proceder a uma rigorosa avaliação do desempenho do Corpo Docente, criando uma carreira e um plano de cargos e salários, em função dos graus e produção científicos e do desempenho e mérito individuais dos Professores.

Em síntese, pode-se observar que os entrevistados avaliam que deveria existir uma qualificação do corpo docente, dando a este tempo integral para o desenvolvimento das atividades na Universidade, além de estabilidade, o que poderia assegurar uma cultura organizacional mais consistente. Assim, estes docentes teriam melhores condições de realizar projetos de pesquisa. Uma outra ação de âmbito institucional evidenciada é a necessidade de 
uma formação propedêutica, dando base em línguas, comunicação, informática para os acadêmicos.

No que se refere a Como podem ser feitas comparações internacionais de custo por aluno, evitando ao máximo as distorções?, observa-se que:

- através do "Padrão de Poder de Compra". As estruturas de custo das Universidades deverão ser semelhantes em termos percentuais. Tomando em conta as diferenças dos custos de vida relativos de casa país.

- qual o percentual gasto em pesquisa no MIT (Instituto de Tecnologia de Massachusetts)? Qual a percentagem dos custos com o corpo docente nos custos totais da Universidade de Harvard? Quanto do seu orçamento anual gasta o ISCTE INDEG, com comunicação e promoção? A partir destes dados poderia criar indicadores para as comparações.

Cabe ressaltar que os informantes-chaves evidenciaram que a melhor solução para evitar distorções para comparações internacionais do custo por aluno é através do "Padrão de Poder de Compra”. Este indicador levaria em consideração o custo de vida em cada país e por conseqüência as Universidades deveriam possuir percentuais semelhantes gastos em ensino, pesquisa e extensão.

\section{CONCLUSÃO}

Este artigo procurou mostrar os fatores que geram uma dificuldade na hora de se comparar os gastos financeiros para se manter um aluno no ensino superior em distintos países.

Quando a comparação do custo por aluno é feita entre países a situação é complexa. Isso porque existem variáveis como políticas de ingressos nas universidades, quadro de pessoal, a tradição administrativa, as leis do país, entre outras que interferem diretamente na relação custo e aluno. Uma alternativa para a comparação internacional do custo por aluno é apontada por Sheehan (1996). A divisão deste valor pelo produto interno bruto per capto do país. Assim, pode-se evitar maiores distorções.

Uma alternativa que se vislumbra também seria criar um "Padrão de Poder de Compra”, tendo em vista que este não é o mesmo nos países, isso ajudaria a evitar distorções maiores ainda. Isso porque, em países mais desenvolvidos, é possível ter valores mais altos, 
porém proporcionalmente menores, se levado em consideração o poder aquisitivo da população.

Uma alternativa para esta comparação seria criar um indicador qualitativo para a comparação. Porque pode acontecer de um país gastar, proporcionalmente ao PIB, muito por aluno, pois tem proporcionalmente menos estudantes matriculados em universidades, porém acabar formando profissionais mais bem preparados. Uma alternativa que se vislumbra seria a criação de um indicador que medisse a quantidade de pesquisas de qualidade realizadas, pois um valor alto de custo por aluno comparativo ao PIB pode indicar também gastos maiores com pesquisas de qualidade.

O que se conclui ao final do artigo é que as comparações do custo por aluno entre instituições de países diferentes não é algo tão simples. É necessária prudência quando realizar estas comparações, porque, como foi ilustrado nesta pesquisa, existem fatores que interferem no custo dos alunos e comparações que não levam em consideração estes fatores podem acarretar em distorções da realidade e comparações irrealistas. Assim, estas distorções podem indicar uma falta de viabilidade, irreal, de aquisições internacionais.

\section{BIBLIOGRAFIA}

AMARAL, Nelson Cardoso. O custo do aluno: uma metodologia para as IFES. Doxa: revista semestral do unileste MG, Coronel Fabriciano, MG : v. 4, n. 8, p. 49-64, jul/dez. 2002.

. Evolução do custo do aluno das IFES: eficiência? Amped. 2005.

A Assessoria Econômica do Ministério do Planejamento. Comparação internacional de gastos governamentais em saúde, educação e previdência. 2005. Disponível em:

$<$ http://www.planejamento.gov.br/orcamento/conteudo/noticias/noticias_2005/051208_compa racao_internacional.htm> Acesso em: 29 de maio de 2009.

CNI. Notas econômicas. CNI Informa. Ano 7, n. 89, 15 mar. 2006. Disponível em: $<$ http://www.cni.org.br/produtos/econ/src/Notas_Economicas89.pdf $>$ Acesso em: 01 de jun. de 2009.

CHURCHILL, G.A. Marketing research: methodological foundations. Chicago: The Dryden Press, 1987.

CRUZ, C. H. de B. A Universidade, a Empresa e a Pesquisa que o país precisa. Disponível em: $<$ http://www.ifi.unicamp.br/ brito/artigos/univ-empr-pesq-rev102003b.pdf $>$ Acesso em: 29 de maio de 2009. 
DIMENSTEIN, Gilberto. Investimento em tecnologia cresce nas empresas, mas ainda é baixo. Folha online. 2001. Disponível em:

$<$ http://www1.folha.uol.com.br/folha/dimenstein/imprescindivel/dia/gd160101.htm $>$ Acesso em: 22 de maio de 2009.

IZIQUE, Cláudia. Crise, Virtudes e oportunidades: importação de equipamentos e insumos eleva o custo de pesquisa no Brasil. Revista Pesquisa Fapesp. Ed 82. Dez. 2002.

GUERRA, Baltazar D’Andrade, CARVALHO, Tito Ferreira. O Comportamento do Consumidor. Disponível em:

$<$ http://www.faculdadesenergia.com.br/espaco_professor/baltasar/comportamento_do_consu midor.doc. $>$ Acesso em: 28/09/2009

LAKATOS, E.V.; MARCONI, M.A. Metodologia Científica. São Paulo: Atlas, 1992.

LOBO, Roberto Leal; FILHO, Silva. Números que confundem. Revista Carta Capital. 28 de abr. de 2004.

MAGALHAES, Elizete Aparecida de et al . Custo do ensino de graduação em instituições federais de ensino superior: o caso da Universidade Federal de Viçosa. Rev. Adm. Pública, Rio de Janeiro, v. 44, n. 3, jun. 2010 . Disponível em $<$ http://www.scielo.br/scielo.php?script=sci_arttext\&pid=S0034-

$76122010000300005 \& \operatorname{lng}=$ pt\&nrm $=$ iso $>$. acesso em 05 jul. 2011

MINAYO, M.C. Pesquisa Social: teoria, método e criatividade. Petrópolois: Vozes, 1998.

RICHARDSON, N. R. Pesquisa Social: métodos e técnicas. São Paulo: Atlas, 1989.

SCHWARTZMAN, Jacques. Políticas de ensino superior no Brasil na década de 90: o financiamento das universidades federais. 1996. Disponível em:

$<$ http://www2.uerj.br/ anped11/19/SCHWARTZ.htm> Acesso em: 02 jul. 2009

SHEEHAN, John. Modelos para la asignación de los fondos públicos entre las universidades. Ministerio de Educación de Argentina. Nuevas direcciones em el financiamiento de la educación superior, 1996. Disponível em:

$<$ http://www.me.gov.ar/spu/documentos/publicaciones/fes.pdf $>$ Acesso em: 22 ago. 2009.

SILVEIRA, L.A. Relação universidade-empresa: fatores propulsores e restritivos no processo de transferência de tecnologia nas empresas catarinenses. Florianópolis, 2005. Tese (Doutorado) - Universidade Federal de Santa Catarina.

SOARES, Thiago Coelho; CERICATO, Domingo. Custo por aluno: algo de fácil comparação?. V Colóquio Internacional de gestão universitária, Mar Del Plata, 2005.

VAHL, Rogério. Temas de Administração universitária. Florianópolis: UFSC, 1991. 
VERGARA, Sylvia Constant. Projetos e relatórios de pesquisa em administração. São Paulo: Atlas, 1998.

VIEIRA, M.M.F. Por uma boa pesquisa (qualitativa) em Administração. Rio de Janeiro: FVG, 2004

YIN, Robert. Estudo De Caso: Planejamento e Métodos. Porto Alegre: Bookman, 2001. 


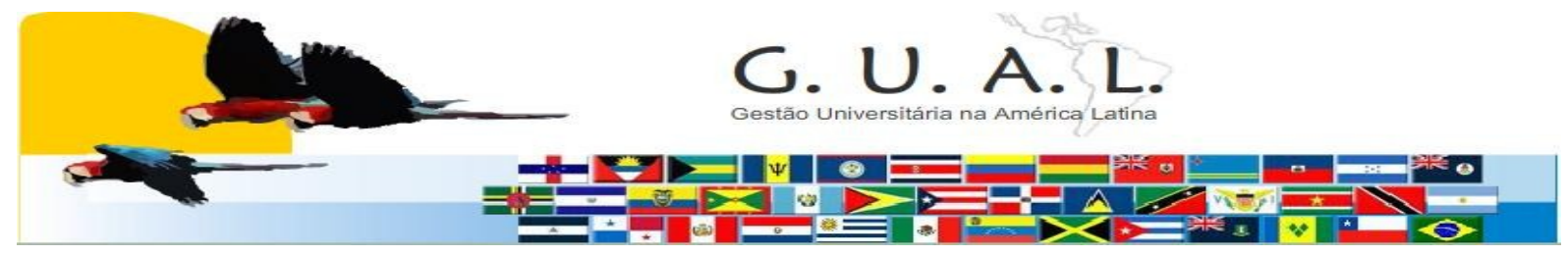

ISSN 1983-4535

\title{
COST COMPARISON BETWEEN INTERNATIONAL UNIVERSITY
}

\author{
Thiago Coelho Soares, Mestre \\ Universidade do Sul de Santa Catarina \\ thiago.soares@unisul.br \\ Gisele Mazon, Mestre \\ Universidade do Sul de Santa Catarina \\ gisele.mazon@unisul.br \\ Ailton Nazareno Soares, Doutor \\ Universidade do Sul de Santa Catarina \\ ailton.soares@unisul.br
}

\begin{abstract}
This article is, objectively, in a comparative analysis of cost per student between universities in different countries. However, we attempted to collect information related to this issue. To this end, we conducted interviews with personalities that could clarify this issue. The results show the importance of observing carefully the differences in international higher education. This time, an adaptation of the Brazilian system to the European or American would be important. Therefore, we concluded that international comparisons should meet at least two basic factors: purchasing power in the country and level of research at the university. Thus, international comparisons between the universities will be less distorted, which will facilitate business prospects.
\end{abstract}

Keywords: Higher education. Cost per student. Internationalization. 